\title{
sciendo
}

\section{Macroeconomic effects of the budget deficit in the Republic of Macedonia}

\author{
Martin Noveski \\ Ministry of Finance, Skopje, Republic of Macedonia \\ martin_noveski@live.com
}

\begin{abstract}
:
Although a decade has passed since the global financial and economic crisis of 2008, the expansionary fiscal policy in Macedonia can still be felt, primarily through an increased level of public expenditures aimed at stimulation of the economic growth. From 2008 onwards, the Republic of Macedonia has continuously recorded a negative budget balance, which affects the resources allocation and the overall economic situation. The question that arises is whether such interference by the Government in the functioning of the market economy is necessary, especially having in mind the EU regulation in this area. Using a multiple regression model for the period 1996-2015, this paper examines the impact of the budget deficit on Gross Domestic Product (GDP) per capita in Macedonia. Results show that the budget deficit is not a statistically significant determinant of GDP per capita, supporting thus the Ricardian equivalence theory. The analysis is conducted on the basis of statistical data from the World Bank's database, as well as data from the National Bank of the Republic of Macedonia. Household final consumption expenditure, the unemployment rate and the official exchange rate of the Macedonian Denar against the U.S. Dollar are also taken into consideration as controlling variables. GDP per capita and household final consumption expenditures are in current prices, with natural logarithms applied, whereas the other variables are in nominal terms. The purpose of this paper is to provide an insight into the empirical relationship between the two main variables of interest and to initiate further discussion and analysis.
\end{abstract}

Keywords: budget deficit, Gross Domestic Product, Ordinary Least Squares, public debt.

JEL classification: C30, C50, $\mathrm{H} 62$.

DOI: $10.2478 /$ crebss-2018-0008

Received: May 11, 2018

Accepted: October 25, 2018

\section{Introduction}

Macroeconomic effects of the budget deficit are subject of vast debate among the economists, but also complicated issue to reach wider consensus, especially after the global financial and economic crisis. Empirical findings in this area vary considerably, depending on the countries and factors taken into account in the analysis, as well as methods used to process and evaluate data. 
Three main schools of economic thought address the issue of the macroeconomic effects of the budget deficit: Neoclassical, Keynesian and Ricardian (Bernheim, 1989). Neoclassical school of thought generally represents the view that the budget deficit has negative effects on economic growth, causing real interest rates to grow and private investments to crowd out of the economy (Barry, Devereux, 1992). Opposite of this view is the Keynesian approach, which points out the counter-cyclical effects of the fiscal policy and the role of the budget deficit as a stabilizer of the economy, emphasizing thus the multiplicative economic effects of the budget deficit, or the "crowding-in" effect (Eisner, 1989). The differences between these two schools of thought arises essentially from their approach and initial assumptions. Keynesian paradigm primarily describes the effects of temporary budget deficits, whereas neoclassical paradigm is focused on the permanent deficits (Bernheim, 1989). Additionally, Keynesian view allows for the possibility that some economic resources are unemployed, and assumes that aggregate consumption is very sensitive to changes in the disposable income (Tas, 1992). As a modification of the Neoclassical standard analysis, Barro (1989) focuses on an alternative theory associated with the name of David Ricardo, or the so-called "Ricardian equivalence theory", which supports the view that budget deficit does not have direct impact on the interest rates and economic growth. According to this theory, increased public consumption, sooner or later, has to be paid and hence the present value of increased taxes in the future corresponds with the additional public spending in the current year, assuming that public expenditures will remain unchanged. In other words, the reduction of taxes in the current year must correspond with the same increase in the present value of future taxes. Besides these three, another alternative view is the "German view", or the Expansionary Fiscal Contraction (EFC) hypothesis, that under certain circumstances fiscal contraction might result in overall economic expansion. This hypothesis is based on the empirical evidences in some EU countries, primarily Denmark and Ireland (Giavazzi, Pagano, 1990).

Although the budget deficit is linked to the fiscal policy of the government, it has its own implications to the monetary policy as well. Namely, in order to maintain stability of the prices in the economy when governments run budget deficit, central banks must conduct restrictive monetary policy. Contrary to the efforts to boost the economy, such limitations lead to reduction in private investments and private final consumption, in particular consumption of durable goods. In a situation where household consumption and private investments are significant drivers of the economic growth, the question that arises is whether it is truly justified to conduct expansionary fiscal policy, and more importantly, to run budget deficit. Usually, regardless of the provenance, political parties after they come to power, prefer the so-called policy of moderate budget deficits, highlighting its positive effects on the economy. No government wants to give up on the attractive capital projects, or to reduce pensions and wages, especially in pre-election period.

In the past period Republic of Macedonia has continuously recorded negative budget balance (with only few exceptions), irrespective to the economic cycles. This resulted in a gradual increase of the public debt, which has reached its maximum of 48.5\% of GDP in 2016 (Ministry of Finance of the Republic of Macedonia, 2017), imposing the need for fiscal consolidation (Trenovski, Tashevska, 2016). However, when it comes to the macroeconomic effects of the budget deficit in the Republic of Macedonia, having in mind the aspirations for EU membership, European legislation in this area is also important. Among other things, the Republic of Macedonia must fulfil certain requirements regarding fiscal policy, budget deficit 
and public debt, in order to start the membership negotiations. Generally, European regulatory framework provided in the Maastricht Treaty of 1992, Stability and Growth Pact, as well as in some other related documents, states that budget deficit and public debt should be within the framework of $3 \%$ and $60 \%$ of GDP correspondingly, striving for a balanced budget in the medium term. Hence, Macedonian Government needs to take these two aspects into account: the impact of the budget deficit on the economic growth and sustainability, and the abovementioned EU requirements.

As a support for the creators of the fiscal policy in Macedonia, this paper addresses the hypothesis that budget deficit has positive and statistically significant influence on the gross domestic product (GDP) per capita of Macedonia, as indicator for the overall economic development. Without going into the structure of the public expenditures and their effectiveness and efficiency, as well as in the tax and customs policy of the country, the focus is on the partial macroeconomic effects. Although this paper provides preliminary empirical analysis, it enriches the scientific literature in this field, for Macedonia and beyond, and brings new perspectives for further research and discussion.

\section{Literature review}

Given that many countries in the world face imbalances in the state budget, macroeconomic implications of the budget deficit are widely examined in the empirical literature. Following previously elaborated theoretical views, very often researchers come up with contradictory empirical findings, supporting some of these theories. Saleh (2003) provides an extensive theoretical and empirical literature review, presenting these differences. The main purpose of his study is to conduct an overview that might be useful for construction and development of models for analysing the macroeconomic impact of the budget deficit. Different conclusions can be reached depending on the quality of the data as well, or the methodology applied. Good example of such contradictory empirical results can be found in the case of Pakistan. Namely, Fatima et al. (2012) investigate the relationship between the budget deficit and economic growth in the period 1978-2009, based on a multiple regression (log-log model) estimated using the OLS method. They find significant and negative impact of the budget deficit on the economic growth, supporting the neoclassical theoretical view. Opposite of that, for almost the same sample period (1976-2006), Nayab (2015) using VAR and VECM models, cointegration analysis and causality tests, finds positive impact of the budget deficit on the economic growth, supporting the Keynesian view on this issue.

Hubbard (2012) provides economic analysis of the government budget deficit in the United States. He finds modest crowding-out of the private investment in U.S., but he also raises his concern about the implications that large increases in the public debt could have on the real interest rates in the country, as well as on the imbalances in the structure of the savings. He points out that the trajectory of government spending will eventually increase the tax burdens and hence lead to reduction of the capital formation, economic growth and living standard.

For our closer surrounding, Gurgul and Lach (2012) analyse the existence of causal dependencies between economic growth and budget/trade deficits for the period 2000-2009 in ten CEE countries in transition. Using Granger causality tests they find evidence that large budget deficit hinders economic growth and its tendency towards more developed EU economies. Similarly, Tešić et al. (2014) addressed this issue for the example of Serbia, taking into account the "twin deficit" hypothesis. Based on the descriptive statistics of the data, they find that growing budget deficit 
in Serbia in the past years and the dominant external financing do not go in favour of the economic development, hence should not be used to boost the economic growth.

For the case of the Republic of Macedonia, Trenovski and Tashevska (2016) elaborate Macedonia's fiscal politics, public debt, and fiscal sustainability. They recommend gradual fiscal consolidation in order to create fiscal space, ensure debt sustainability and build fiscal buffers. Fiscal consolidation should be achieved by cuts in the current expenditures, reforms of the pensions and social benefits, as well as prioritization of the capital expenditures. On the other hand, having in mind the Government's strategic decision to maintain low and flat tax, they suggest the increase of the public revenues to be done by expansion of the tax base and improving of the tax collection efficiency. They also emphasize the need of good coordination between the fiscal and monetary policy, as prerequisite for achieving the macroeconomic goals of the country.

Fiscal consolidation is recommended every time when discussing the consequences of increased budget deficit. However, it should be carried out carefully, since it might cause decrease in the output and the final consumption (Keynesian view). Expansionary Fiscal Contraction (EFC) hypothesis on the contrary, claims that under certain circumstances, a major reduction in government spending will expand private consumption, resulting in overall economic expansion. Bergman and Hutchison (2010) test this hypothesis for the Danish fiscal reform from 1983. They combine structural VAR with an event study element to provide empirical evidence that consumption and output in Denmark were strongly stimulated by the fiscal contraction. However, it is important to highlight that their results are valid only for large and credible fiscal consolidations. Effects of the fiscal consolidations in EU are also examined by Giudice et al. (2003). Based on the cross-country analysis, they provide evidence that fiscal consolidations obtained, through expenditure cuts rather than revenue increases, are followed by an acceleration of the economic growth. Similarly, Briotti (2005) elaborates on the conditions under which consolidations should be carried out, without threatening the economic growth. The conclusion is that under some circumstances austerity measures might lead to economic expansion.

\section{Data and methodology}

For the purposes of this research data from the World Bank database, for the period from 1996 to 2015 (20 observations), have been used (World Bank, 2017). The only exception regarding the data source is the budget balance of the Republic of Macedonia, which is taken from the National Bank of the Republic of Macedonia (National Bank of the Republic of Macedonia, 2017). The methodological approach is consisted of development and estimation of relevant econometric model that would examine the relationship between the budget deficit and gross domestic product (GDP) per capita in Macedonia. Considering the limitations of the small sample size, as well as the intention to take into account other relevant factors, the developed model is a multiple regression, expressing GDP per capita as a function of the budget deficit, household final consumption expenditure, unemployment and the official exchange rate of the Macedonian Denar against the U.S. Dollar. Since GDP per capita and the household final consumption expenditure are expressed in current U.S. Dollars, log terms are applied to these variables. Current U.S. Dollars are used for these two variables in order to assure consistency between the variables, since methodologically the budget deficit is calculated using nominal GDP. 
Given that the focus of this paper is primarily on the relationship between the budget deficit and GDP per capita, three other independent variables are used for control purposes, to avoid omitted variable bias. The selection of these control variables was preceded by a broad analysis of many other factors, such as inflation, real interest rates, money supply, public debt, foreign investment, etc. The aim of this approach was to investigate the influence of as many macroeconomic and monetary indicators as possible, and to select only the most statistically relevant determinants of GDP per capita. On the other hand, this selection process also served as a solid test for the robustness of the estimated coefficient of the budget deficit, since it remained statistically insignificant regardless of the model specification. The reason why the analysis addresses these variables is their theoretical and empirical connection to the economic growth. For example, final consumption can be an important driver of the economic development, whereas unemployment could lead to an increase in the gap between the potential and real GDP. Also, inflation can sometimes boost the economy and lead to nominal GDP growth, but it undermines the stability of the economy and can negatively affect the investments. However, many of these variables were excluded from the final model, either because they were statistically insignificant, or violated some of the assumptions of the classical linear regression model (CLRM), primarily causing multicorellation (Gujarati, Porter, 2009).

As for the model estimation, the ordinary least squares (OLS) method was used as an estimation technique, accompanied by a series of diagnostic tests that have been performed to check the fulfilment of the assumptions of the CLRM. Although there are many different models and methods of estimation that can be applied in the analysis of this issue, this particular model is chosen because of its simplicity and widely affirmed empirical reliability.

Prior to the model estimation, the analysis covered descriptive statistics of the data (presented in Table 1), correlation and unit root test. Augmented Dickey-Fuller (ADF) test was used in this regards, whereby, based on the graphical illustration, for three of the variables (GDP per capita, household final consumption expenditure and unemployment) besides the intercept, a trend component was also included in the calculation. However, shifts and structural breaks in the data were not taken into account for any of the variables.

Table 1: Descriptive statistics

\begin{tabular}{|l|r|r|r|r|r|r|r|}
\hline \multicolumn{1}{|c|}{ Variable } & \multicolumn{1}{c|}{ Mean } & \multicolumn{1}{c|}{ Median } & \multicolumn{1}{c|}{ Max } & \multicolumn{1}{c|}{ Min } & St. Dev. & Obs. & Integ. \\
\hline GDP per capita & $3,402.0$ & $3,181.7$ & $5,469.2$ & $1,774.8$ & $1,384.5$ & 20 & I(2) \\
\hline $\begin{array}{l}\text { Net lending (+) / Net } \\
\text { borrowing (-) }\end{array}$ & -1.8 & -1.4 & 2.4 & -5.9 & 2.1 & 20 & I(0) \\
\hline $\begin{array}{l}\text { Household final } \\
\text { consumption expenditure }\end{array}$ & 5.2 & 5.2 & 7.9 & 2.6 & 2.1 & 20 & I(2) \\
\hline Unemployment & 32.9 & 32.3 & 37.3 & 26.1 & 3.1 & 20 & I(2) \\
\hline Official exchange rate & 51.0 & 49.0 & 68.0 & 40.0 & 7.9 & 20 & I(2) \\
\hline
\end{tabular}

Source: Author's calculation.

\section{Econometric model}

As a response to the global economic crisis, Macedonian Government has decided for a continuous fiscal stimulus of the economy in the following period, guided by the Keynesian approach. The intentions were to increase the output and the production by undertaking measures aimed at the aggregate demand. However, the 
increasing trend of the GDP per capita that followed might not be necessarily related to the expansionary fiscal policy of the Government and the budget deficit per se. On the contrary, the correlation coefficient between these two variables indicates rather weak statistical relationship (-0.32 for the whole sample, or -0.5 for the period from 2008 onwards).

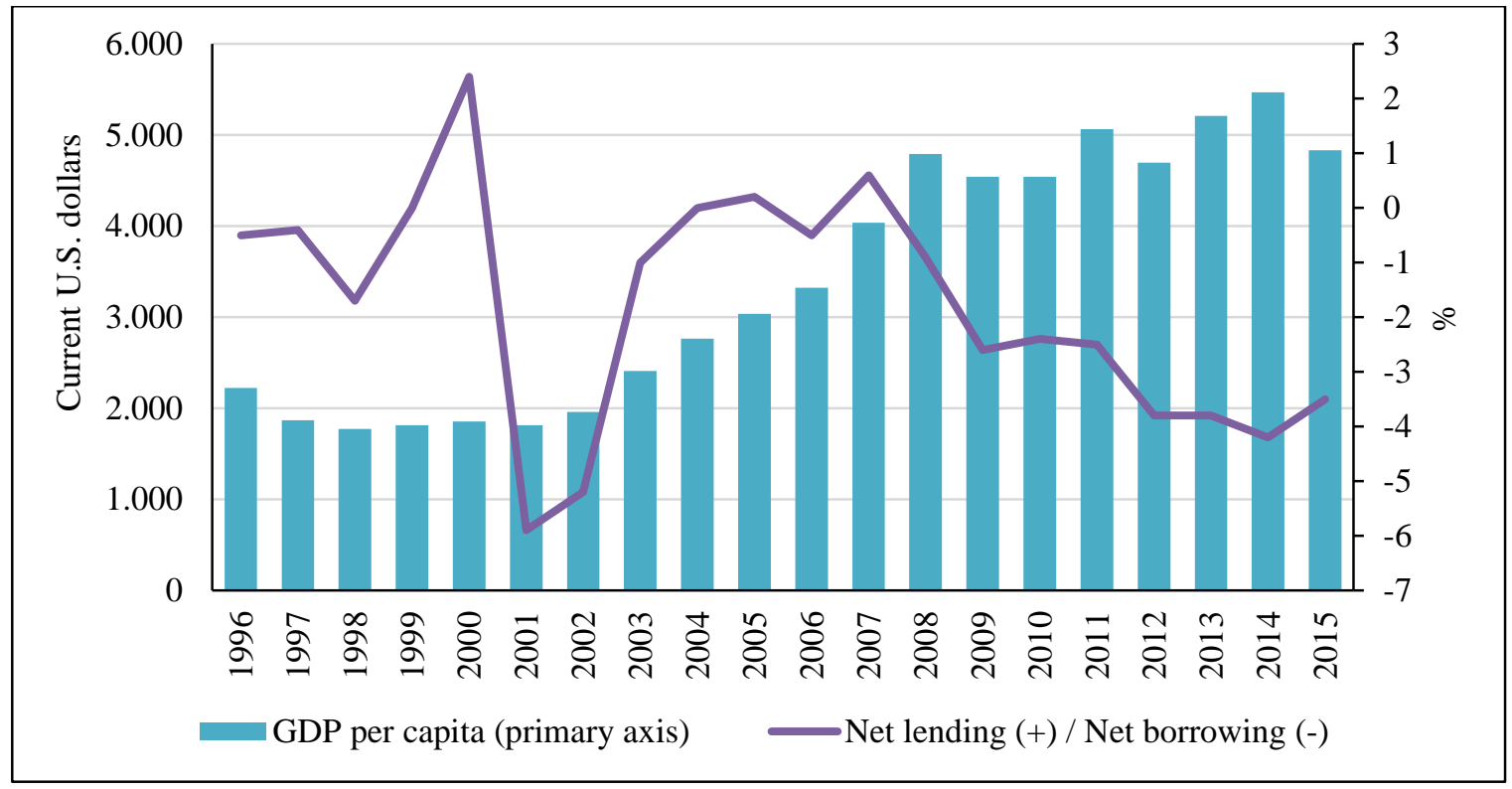

Figure 2: GDP per capita and budget balance of Macedonia Source: World Bank, 2017, National Bank of the Republic of Macedonia, 2017.

Based on the provided theoretical and empirical literature, in order to further investigate this relationship, the following econometric model of GDP per capita is developed:

$$
\text { GDP=f(DEFICIT, HFCE, UN, EXC), }
$$

where GDP - GDP per capita (in current US Dollars), DEFICIT - Budget balance (\% of GDP), multiplied by $(-1)$, HFCE - Household final consumption expenditure (in current US Dollars), UN - Unemployment rate, EXC - Official exchange rate.

Estimated parameters of the model are presented in Table 2. Based on these estimates and with respect to the dominant theoretical views, can be noted that the variable of interest, budget deficit, has estimated coefficient of -0.00236 , which means that an increase in the budget deficit of 1 percentage point would cause average decrease in GDP per capita of $0.24 \%$, everything else equal. However, this estimated coefficient is statistically insignificant even at 0.1 significance level $(p=0.3286)$, meaning that $\mathrm{H}_{0}: \beta_{1}=0$ cannot be rejected, supporting thus the Ricardian equivalence theory. As for the other estimated coefficients, in order not to expand the scope of the paper, they will not be subject of discussion.

Table 2: Model estimates

\begin{tabular}{|l|r|r|r|c|}
\hline \multicolumn{5}{|l|}{ Dependent Variable: LOG(GDP) } \\
\hline \multicolumn{1}{|c|}{ Independent Variables } & \multicolumn{1}{l|}{ Coefficient } & \multicolumn{1}{c|}{ Std. Error } & \multicolumn{1}{c|}{ t-Statistic } & \multicolumn{1}{c|}{ Prob. } \\
\hline C & -9.535390 & 0.393312 & -24.2438 & 0.0000 \\
\hline DEFICIT & $-\mathbf{0 . 0 0 2 3 6 0}$ & $\mathbf{0 . 0 0 2 3 3 7}$ & $-\mathbf{1 . 0 0 9 8}$ & $\mathbf{0 . 3 2 8 6}$ \\
\hline LOG(HFCE) & 0.836385 & 0.014580 & 57.3653 & 0.0000 \\
\hline UN & -0.022204 & 0.001874 & -11.8458 & 0.0000 \\
\hline EXC & -0.006392 & 0.000783 & -8.1624 & 0.0000 \\
\hline
\end{tabular}

Source: Author's calculation. 
Regarding the goodness of fit, the model is statistically significant at 0.01 significance level $(F=3,310)$, with adjusted $R^{2}$ coefficient of 0.9986 . The estimated model fully meets all of the assumptions of the classical linear regression model, meaning that residuals are normally distributed, with zero mean and constant variance, and no serial correlation of first and second order. Also, there is no multicollinearity and the model is correctly specified.

Table 3: Model diagnostics

\begin{tabular}{|c|c|c|c|c|}
\hline Test & Null hypothesis & test stat. & prob. & conclusion \\
\hline \multicolumn{5}{|c|}{ Heteroskedasticity } \\
\hline $\begin{array}{l}\text { White test (no } \\
\text { cross terms) }\end{array}$ & \multirow{2}{*}{ Residuals are homoskedastic } & 3.22 & 0.521 & HO not rejected \\
\hline $\begin{array}{l}\text { Breusch-Pagan- } \\
\text { Godfrey test }\end{array}$ & & 2.83 & 0.587 & HO not rejected \\
\hline \multicolumn{5}{|c|}{ Serial correlation } \\
\hline $\begin{array}{l}\text { Durbin-Watson } \\
\text { statistics }\end{array}$ & $\begin{array}{l}\text { Is there 1st ordred serial } \\
\text { correlation }\end{array}$ & 2.07 & & No serial correl. \\
\hline \multirow{2}{*}{ LM test } & No 1st order serial correlation & 0.17 & 0.684 & HO not rejected \\
\hline & No 2nd order serial correlation & 0.23 & 0.892 & HO not rejected \\
\hline \multicolumn{5}{|c|}{ Residuals unit root } \\
\hline ADF test & Residuals have unit root & -4.61 & $1 \mathrm{E}-04$ & $\mathrm{HO}$ is rejected \\
\hline \multicolumn{5}{|c|}{ Multicollinearity } \\
\hline Correlation & Correlation coefficients of the X's & $r<0.8$ & & No multicoll. \\
\hline VIF (for all X's) & No multicollinearity & $\mathrm{VIF}<5$ & & HO not rejected \\
\hline \multicolumn{5}{|c|}{ Normal distribution of the residuals } \\
\hline Jarque-Berra test & Residuals are normally distributed & 2.21 & 0.332 & HO not rejected \\
\hline \multicolumn{5}{|c|}{ Model specification } \\
\hline \multirow{2}{*}{ Ramsey RESET test } & Errors in the spec. ( 1 fitted term) & 0.01 & 0.914 & HO not rejected \\
\hline & Errors in the spec. (2 fitted terms) & 0.55 & 0.591 & HO not rejected \\
\hline
\end{tabular}

Source: Author's calculation.

However, the unusually high $\mathrm{R}^{2}$ coefficient might be an indicator of a spurious regression, moreover when most of the variables are non-stationary at levels. Theory suggests that in case of spurious regression $R^{2}$ is greater than Durbin-Watson (DW) statistics ("rule of thumb"), and there is high risk of type I error, or false rejection of the null hypothesis $\beta_{i}=0$ (Baumohl, Lyocsa, 2009). In this case DW statistics is around 2 $\left(R^{2}<D W\right)$, all CLRM assumptions are met, and the null hypothesis for the main parameter of interest (budget deficit) is not rejected anyway, so the selection of the OLS method as most appropriate can be considered as justified. Also, one needs to be aware of the small sample size, which might be inadequate for some other available techniques (co-integration analysis, VAR and VECM models, etc.). The reliability of these alternative models heavily depends on the number of included lags, which also determines the number of parameters that need to be estimated. small number of degrees of freedom in that case might seriously affect the efficiency of the estimates, or even make the estimation impossible.

\section{Limitations and assumptions}

Although the estimated model can be considered as statistically significant and reliable, several important limitations and assumptions related to the overall political and economic situation in the country need to be emphasized. Namely, the most 
important limitation when it comes to the Republic of Macedonia is the absence of fully implemented, standardized and comparable methodology for government finance statistics (GFS), which inevitably leads to differences in the fiscal data when compared to the other countries, especially EU member countries, due to the different method of calculation. Another source of miscalculations could be the lack of strictly defined data exchange channels between the public institutions in the country and the absence of integrated IT software for public finance management to support the data collection and management. These limitations could significantly affect the model results and even lead to irrelevant conclusions. Therefore, data from reliable data sources is used, but still the quality and comparability are questionable and thus very strong assumptions.

Other very important and strong assumption is the effectiveness and efficiency of the public finance management in the country. In order to analyse the true macroeconomic implications of the budget deficit, the effectiveness and efficiency in the revenue collection process, as well as in the public spending should ne on the highest possible level. In this regards, strong institutional system, consisted of well developed, independent and integrated institutions is assumed.

\section{Conclusions}

As a main subject of this paper, the focus is primarily on the empirical effects of the budget deficit in Macedonia to GDP per capita. One of the main responsibilities of the government is to provide good environment for sustainable development of the country, making optimal use of the available resources. However, having in mind the size and the power of the economy, the government must be very careful about every action it takes, since it might have serious consequences. Although public finance management is huge responsibility, it is at the same time powerful tool for setting the path towards the long-run goals and strategic priorities.

Based on the above elaboration, one can conclude that the economic theory and the empirical literature do not provide clear consensus regarding macroeconomic effects of the budget deficit. Namely, depending on the level of development of the country, its specific socio-economic and political environment, as well as the quantitative methods applied, results may significantly vary, supporting different theoretical views. In the case of the Republic of Macedonia, based on a multiple regression model and empirical data for the period from 1996 to 2015, budget deficit is not statistically significant explanatory variable of GDP per capita, even at 0.1 significance level. However, having in mind the limitations related to the country's specifics, one could not jump into conclusion that budget deficit is bad for Macedonian economy. On the contrary, the conclusion would be that it does not directly affect the dependent variable, given the political and economic environment, although it might have impact on the other determinants of the economic growth, as suggested by the theory. Therefore, this should be a base for further, more detailed analysis.

Although Macedonian budget deficit and public debt are within the EU framework, there are still risks that might arise. Macedonian government should urgently stop the increasing trend of the public debt and stabilize the budget deficit, in order to strengthen the long-run sustainability of the economic growth. Further accumulation of public debt could have negative consequences on the credit rating of the country and cause difficulties for financing the deficit, in terms of higher interest payments. In addition, lower budget deficit will relax the pressure on the real interest rates in the economy and the overall monetary policy, hence will provide good environment for stable economic growth. Despite of the concerns that fiscal 
consolidation would inevitably lead to decrease in the output and consumption, contemporary empirical literature in this area provides evidences that if carried out properly, fiscal consolidation might even have positive impact on the economic growth in medium term.

\section{References:}

1. Barro, R. J. (1989). The Ricardian Approach to Budget Deficits. Journal of Economic Perspectives, Vol. 3, No. 2, pp. 37-54.

2. Barry, F. G., Devereux, M. B. (1992). Crowding Out Effects of Government Spending. The Economic and Social Review, Vol. 23, No. 3, pp. 199-221.

3. Baumohl, E., Lyocsa, S. (2009). Stationarity of time series and the problem of spurious regression. MPRA Paper, No. 27926, pp. 1-16. Available at http://mpra.ub.unimuenchen.de/27926/ [10 May 2018].

4. Bergman, U. M., Hutchinson, M. (2010). Expansionary Fiscal Contractions: Re-evaluating the Danish Case. International Economic Journal, Vol. 24, No. 1, pp. 71-93.

5. Bernheim, B. D. (1989). A Neoclassical Perspective on Budget Deficits. Journal of Economic Perspectives, Vol. 3, No. 2, pp. 55-72.

6. Briotti, M. G. (2005). Economic Reactions to Public Finance Consolidation: A Survey of the Literature. European Central Bank Occasional Paper Series, No. 38, pp. 1-31.

7. Eisner, R. (1989). Budget Deficits: Rhetoric and Reality. Journal of Economic Perspectives, Vol. 3, No. 2, pp. 73-93.

8. Fatima, G., Ahmed, M., Rehman, W. (2012). Consequential Effects of Budget Deficit on Economic Growth of Pakistan. International Journal of Business and Social Science, Vol. 3 No. 7, pp. 203-208.

9. Giavazzi, F., Pagano, M. (1990). Can Severe Fiscal Contractions Be Expansionary? Tales of Two Small European Countries. NBER Macroeconomics Annual, Vol. 5, pp. 75-122. Available at http://www.nber.org/chapters/c10973 [10 May 2018].

10. Giudice, G., Turrini, A., Veld, J. (2003). Can fiscal consolidations be expansionary in the EU? Ex-post evidence and ex-ante analysis. European Economy - Economic Papers, No. 195, pp. 1-35.

1 1.Gujarati, D. N., Porter, D. C. (2009). Basic Econometrics. McGraw-Hill/Irwin, New York.

12. Gurgul, H., Lach, L. (2012). Two Deficits and Economic Growth: Case of CEE Countries in Transition. AGH Managerial Economics, No. 12, pp. 79-108.

13. Hubbard, G. (2012). Consequences of Government Deficits and Debt. International Journal of Central Banking, Vol. 8, No. S1, pp. 203-235.

14. Ministry of Finance of the Republic of Macedonia (2017). Stock of debt (\% of GDP). Available at https://www.finance.gov.mk/en/node/2678 [10 May 2018].

15.Nayab, H. (2015). The Relationship between Budget Deficit and Economic Growth of Pakistan. Journal of Economics and Sustainable Development, Vol. 6, No. 11, pp. 85-90.

16.Saleh, A. S. (2003). The Budget Deficit and Economic Performance: A Survey. Department of Economics, University of Wollongong, Working Paper 03-12, pp. 1-56. Available at http://ro.vow.edu.au/commwkpapers/78 [10 May 2018].

17. National Bank of the Republic of Macedonia (2017). Basic economic data. Available at http://nbrm.mk/osnovni_ekonomski_pokazateli-en.nspx [10 May 2018].

18.Tas, R. (1992). Theoretical and Empirical Aspects of Budget Deficits. Ankara University Faculty of Political Sciences Journal, Vol. 47, No. 3, pp. 327-341.

19.Tešić, A., llić, D., Đelić, A. T. (2014). Consequences of Fiscal Deficit and Public Debt in Financing the Public Sector. Economics of Agriculture, Vol. 61, No. 1, pp. 177-194.

20.Trenovski, B., Tashevska, B. (2016). Fiscal Sustainability in Macedonia on its path towards EU. MPRA Paper, No. 76321, pp. 1-16. Available at https://mpra.ub.uni-muenchen.de/76321/ [10 May 2018].

21.World Bank (2017). Time series indicators for the Republic of Macedonia. Available at https://data.worldbank.org/country/macedonia-fyr?view=chart [10 May 2018]. 


\section{About the author}

Martin Noveski works at the Budget and Funds Department in the Ministry of Finance of the Republic of Macedonia, and has a Master's Degree in Econometrics and Quantitative Economics, applying statistical methods in business and economy. During his career, he has participated in numerous projects, among which the EU funded Project "EU Scheme for Young Professionals in the Western Balkans", managed by the European Commission and implemented by the British Council. In the period December 2015 - November 2017 Martin Noveski was also the RTA counterpart of the Twinning Project "Strengthening the medium term budgeting for effective public financial management", implemented by HAUS Finnish Institute for Public Management. Besides his interest in statistics and econometrics, his fields of interest include economic development, macroeconomic and fiscal policy, as well as public finance management. Author can be contacted at: martin_noveski@live.com. 